\title{
Assessment of Failure of Prosthesis in Fixed Prosthodontics Among Patients Reporting To A Teaching Dental Hospital of Karachi
}

\author{
Asma $\mathrm{Naz}^{1}$ \\ BDS, FCPS \\ Hira Musharraf ${ }^{2}$ \\ BDS, FCPS \\ Atif Jawad ${ }^{3}$ \\ BDS, FCPS \\ Kainat $\mathrm{Zia}^{4}$ \\ BDS \\ Bharat Kumar ${ }^{5}$ \\ BDS, FCPS \\ Muneeb Ahmed Lone ${ }^{6}$ \\ BDS, FCPS
}

OBJECTIVE: The purpose of this study was to evaluate reasons of failure for conventional crowns and fixed partial dentures in patients reporting to the Prosthodontics OPD.

METHODOLOGY: This cross sectional study was carried out in the Department of Prosthodontics at Jinnah Medical and Dental College, Karachi from December 2018 to September 2019. A total of 149 patients were enrolled in the study using nonprobability, consecutive sampling technique. The demographic data was recorded and patients were examined to assess the cause of failure of fixed dental prosthesis. SPSS version 22 was used for statistical analysis.

RESULTS: The mean age of the 149 prosthesis examined was $4.78 \pm 4.37$ years. Most of the failures $130(87.2 \%)$ were due to biologic causes. Almost all of the patients $(98.0 \%)$ cleaned their teeth by brushing. The mean life span of the 145 porcelain fused to metal prosthesis examined was $4.89 \pm 4.38$ years. Most of the failed restorations were single unit with a mean prosthesis age of $4.27 \pm 4.26$ years while 7 (4.7\%) fixed partial dentures had greater than 5 units and had a mean life of $11.6 \pm 5.45$ years. There was a statistically significant difference in the failure of prosthesis according to its position in the dental arch $(\mathrm{p}<0.02)$ CONCLUSION: Fixed dental prostheses provide one of the best treatment modalities for replacing teeth. At present the average life of prosthesis at 4 years is less than satisfactory. To improve the longevity of these restorations it is necessary to have proper patient selection, diagnosis, treatment planning, clinical and technical skills. It is also essential to educate the patient about proper oral hygiene and prosthesis maintenance so that the life span of fixed prosthesis is increased. KEYWORDS: porcelain fused to metal restoration, fixed dental prosthesis, biologic failure

HOW TO CITE: Naz A, Musharraf H, Jawad A, Zia K, Kumar B, Lone MA. Assessment of failure of prosthesis in fixed prosthodontics among patients reporting to a teaching dental hospital of Karachi. J Pak Dent Assoc 2020;29(3):105-109. DOI: https://doi.org/10.25301/JPDA.293.105

Received: 23 November 2019, Accepted: 12 May 2020

\section{INTRODUCTION}

$\mathrm{L}$ oss of teeth is a common condition affecting individuals globally. ${ }^{1}$ A systematic review on the global burden of severe tooth loss indicated that about $2.3 \%$ of the population was edentate in $2010 .^{2}$ As there is such a large number of people who have missing teeth,

1. Associate Professor, Department of Prosthodontics, Jinnah Medical \& Dental College.

2. Senior Registrar, Department of Prosthodontics, Dow Dental College.

3. Assistant Professor, Department of Prosthodontics, Bhittai Dental and Medical College.

4. Demonstrator, Department of Prosthodontics, Bhittai Dental and Medical College.

5. Assistant Professor, Department of Prosthodontics, Dow Dental College.

6. Assistant Professor, Department of Prosthodontics, Dr Irshad-ul-Ebad Khan Institute of Oral Health Sciences.

Corresponding author: "Dr. Hira Musharraf" < hira.musharraf@duhs.edu.pk > there is a high demand to replace missing teeth to improve mastication and esthetics. ${ }^{3}$ Fixed prosthodontics allows replacement of missing teeth by restorations that are not readily removed from the mouth. ${ }^{4}$ Today, crowns and fixed partial dentures are one of the most commonly used prosthesis by dental practitioners to replace missing teeth. ${ }^{5} \mathrm{~A}$ crown is a fixed extra-coronal artificial restoration that replaces the lost tooth structure by covering the coronal portion of a natural tooth with various materials such as cast metal alloy, metal- porcelain, dental porcelain, resins or more recently zirconia. A fixed partial denture is defined as a fixed restoration which replaces one or more missing teeth and is attached to natural teeth or an implant. ${ }^{4}$ 
A crown provides one of the best options to restore an endodontically treated tooth. It is also used widely to restore form and function when a substantial amount of tooth structure has been lost due to caries, trauma, or parafunctional habits. The goal of these restorations is to restore esthetics, function and comfort. ${ }^{6}$ When missing teeth are replaced by the provision of fixed partial dentures after proper treatment planning, they can provide acceptable function, esthetics, value for money and longevity. ${ }^{5,7}$ However, in case of improper treatment planning, they are more likely to fail prematurely and lead to irreversible damage to the teeth and supporting structures. In recent years, several investigators have taken great interest in investigating the life span and long-term quality of fixed dental prosthesis. ${ }^{8}$ Some of the common failures in fixed bridge prosthodontics are loose retainers, fracture of soldered joints, fracture of porcelain, fracture of the abutment teeth or voids in retainer or pontic. Failure of theses restorations may also lead to recurrent caries or loss of abutment teeth. ${ }^{5}$

To be able to prevent these failures when providing a fixed dental prosthesis, clinicians should have adequate knowledge and skills regarding diagnosis, examination, treatment planning and manual dexterity to execute the planned treatment. ${ }^{8,9}$

The purpose of this study was to evaluate the reason of the failure of conventional crowns and fixed partial dentures in patients reporting to the Prosthodontics OPD.

\section{METHODOLOGY}

The study was carried out in the Department of Prosthodontics of Jinnah Medical and Dental College from December 2018 to September 2019. An institutional ethical committee approval (BMDC/R\&D/ERC/2019-05) was taken before commencing the study. The sample size was calculated using OpenEpi software v.3.01. Taking the prevalence of failure of fixed restorations to be $13.8 \%$, confidence interval $92 \%$ and margin of error 5\%; the sample size came out to be 149 patients. ${ }^{10}$ Non-probability, consecutive sampling technique was used to include patients in the study. Patients who reported to the OPD of Jinnah Medical and Dental College in the Department of Prosthodontics with problems related to their crowns or fixed partial dentures (FPD) were selected for the study after consent was obtained from them. Any prosthesis that required replacement or repair was considered as failed. All the necessary data was entered in a structured form. This included the patients' demographics i.e. name, gender and age. Other data recorded included the age of the prosthesis, the material of prosthesis, cleaning method and frequency adopted by the patient, the arch along with the location of restoration in the arch, the number of units of fixed restoration and the cause of failure was noted. The examination of patients was carried out by the principal investigator.

The failures were classified as biologic, mechanical and esthetic. Biologic failures included endodontic failures, compromised periodontal conditions, gingivitis, secondary caries, mobility, poor oral hygiene, root recession, pain and swelling, bone resorption, abscess formation, food impaction and pocketing. Mechanical failures included dislodged prosthesis, improper crown preparation, and fracture of an abutment, prosthesis fracture and loss of restoration along with abutment teeth. Esthetic failures included shade mismatch and contour discrepancies. ${ }^{5}$

SPSS version 22 was used for data entry and analysis. Data was analyzed to record the frequency and percentages of failure of the fixed prosthesis according to cause of failure, the material of prosthesis, location of the prosthesis in the arch, the number of units in a prosthesis, the method and regularity of cleaning teeth used by a patient. Mean \pm SD were calculated for age distribution and life span of prosthesis. Stratification of data was done in terms of gender, age, material of prosthesis, the location of the restoration in the arch, number of units of fixed restoration and the cause of failure.

\section{RESULTS}

Out of the 149 patients examined, there were 39 (26.2\%) males and $110(73.8 \%)$ females. The mean age of the study population was 42.4 years; ranging from $15-81$ years of age. The mean age of the prosthesis examined in the study was $4.78 \pm 4.37$ years. The reasons for failure of restorations are shown in Figure 1.

Out of the 149 patients, $146(98.0 \%)$ cleaned their teeth

Figure 1: Reasons of failure of fixed restorations
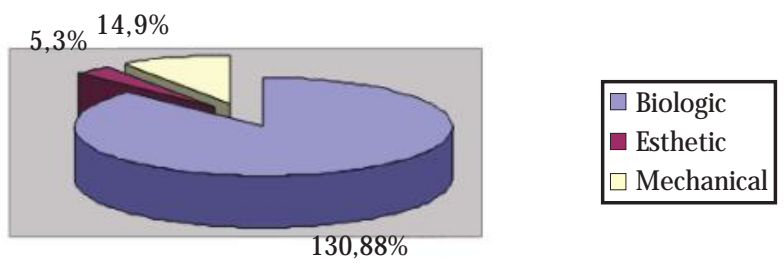

by brushing alone, while brushing plus flossing; use of brushing and miswak and use of floss alone was performed by 1 patient each. Eighty-four (56.4\%) patients cleaned their teeth once daily, $50(33.6 \%)$ patients cleaned their teeth twice daily, 11 (7.4\%) cleaned their teeth three times daily, $4(2.7 \%)$ were found to clean their teeth occasionally. Among the 149 prosthesis analyzed 145 (97.3\%) were made of porcelain fused to metal while $4(2.7 \%)$ were all metal. The mean prosthesis life according to the material of 
Naz A/ Musharraf H/ Jawad A/ Zia K/ Kumar B/ Lone MA

Table 1: Failure percentage and mean prosthesis age according to material of prosthesis

\begin{tabular}{|l|l|l|}
\hline Material of Prosthesis & Frequency n (\%) & $\begin{array}{l}\text { Prosthesis age } \\
\text { Mean } \pm \text { SD (years) }\end{array}$ \\
\hline Porcelain fused to metal & $145(97.3)$ & $4.89 \pm 4.38$ \\
\hline All metal & $4(2.7)$ & $0.9 \pm 0.83$ \\
\hline
\end{tabular}

Table 2: Failure percentage and mean prosthesis age according to dental arch

\begin{tabular}{|l|l|l|}
\hline Dental Arch & $\begin{array}{l}\text { Frequency n } \\
(\%)\end{array}$ & $\begin{array}{l}\text { Prosthesis age } \\
\text { Mean } \pm \text { SD (years) }\end{array}$ \\
\hline Maxillary arch & $\mathbf{7 4 ( 4 9 . 7 )}$ & $\mathbf{5 . 0 8} \pm \mathbf{5 . 0 6}$ \\
\hline Mandibular arch & $\mathbf{7 5 ( 5 0 . 3 )}$ & $4.48 \pm 3.57$ \\
\hline
\end{tabular}

Table 3: Failure percentage and mean prosthesis age according to location of prosthesis

\begin{tabular}{|l|l|l|}
\hline Location of prosthesis & Frequency n (\%) & $\begin{array}{l}\text { Prosthesis age } \\
\text { Mean } \pm \text { SD (years) }\end{array}$ \\
\hline Anterior & $20(13.4)$ & $6.46 \pm 7.32$ \\
\hline Posterior & $119(79.9)$ & $4.30 \pm 3.63$ \\
\hline Anterior to posterior & $10(6.7)$ & $7.04 \pm 3.61$ \\
\hline
\end{tabular}

Table 4: Relationship of location of tooth with the dental arch

\begin{tabular}{|c|c|c|c|c|}
\hline \multirow{2}{*}{$\begin{array}{c}\text { Location of } \\
\text { prosthesis }\end{array}$} & \multicolumn{3}{|c|}{ Dental Arch } & p-value \\
\cline { 2 - 5 } & $\begin{array}{c}\text { Maxillary Arch } \\
\text { (n) }\end{array}$ & $\begin{array}{c}\text { Mandibular Arch } \\
\text { (n) }\end{array}$ & Total (n) & \\
\hline Anterior & 12 & 8 & 20 & 1.8 \\
\hline Posterior & 58 & 61 & 119 & 0.02 \\
\hline $\begin{array}{c}\text { Anterior- to } \\
\text { Posterior }\end{array}$ & 4 & 6 & 10 & 2.2 \\
\hline Total & 74 & 75 & 149 & \\
\hline
\end{tabular}

p-value significant $<0.05$

Table 5: Failure percentage and mean prosthesis age according to number of units

\begin{tabular}{|l|l|l|}
\hline Number of Units & Frequency $\mathrm{n}(\%)$ & $\begin{array}{l}\text { Mean prosthesis age } \\
\text { (years) }\end{array}$ \\
\hline 1 unit & $89(59.7)$ & $4.27 \pm 4.26$ \\
\hline 2 unit & $14(9.4)$ & $4.05 \pm 2.66$ \\
\hline 3 unit & $25(16.8)$ & $4.92 \pm 4.59$ \\
\hline 4 unit & $10(6.7)$ & $4.51 \pm 1.79$ \\
\hline 5 unit & $4(2.7)$ & $6.6 \pm 4.18$ \\
\hline Greater than 5 & $7(4.7)$ & $11.58 \pm 5.45$ \\
\hline
\end{tabular}

prosthesis is shown in Table 1. Seventy-four $(49.7 \%)$ patients had failing restorations in maxilla while 75 (50.3\%) patients presented with these restorations in mandible. The mean prosthesis life according to the dental arch is shown in Table 2. Results showed that 119 (79.9\%) failed restorations were in posterior quadrants, 20(13.4\%) were in anterior
Assessment of failure of prostheses in fixed prosthodontics

quadrants whereas the remaining $10(6.7 \%)$ fixed restorations extended from the anterior till the posterior segment. The number of failing prostheses according to the position in the arch and its mean life is shown in Table 3. There was a statistically significant difference in the failure of prosthesis according to their position in the dental arch $(\mathrm{p}<0.02)$ table 4. It was found that $89(59.7 \%$ ) failed restorations were of a single unit, $14(9.4 \%)$ were two units, $25(16.8 \%)$ were 3 units, $10(6.7 \%)$ were four units, $4(2.7 \%)$ were five units and $7(4.7 \%)$ fixed partial dentures had greater than 5 units. The number of failed prostheses and their mean age according to the number of units is shown in Table 5 .

\section{DISCUSSION}

Crown and bridge failures are one of the most routinely encountered problems by the dentists. 8 A recent systematic review revealed the cumulative 5-year survival rates of 93.5\% for fixed partial dentures with a complication rate of $27.6 \% .{ }^{11}$ Bjarni et al also reported a survival rate of $89.1 \%$ for fixed partial dentures after 10 years in service. ${ }^{12}$ Internationally, several surveys have been conducted to assess the mean age that the prosthesis lasts for. ${ }^{10,13,14}$ The mean prosthesis age in this study was found to be 4.8 years; that is comparatively less than the mean age found by Prasad et $\mathrm{al}^{13}$ i.e. 7.3 years and Walton et $\mathrm{al}^{14} 8.3$ years but longer than the mean prosthesis age found by Cheung et al i.e. 2.8 years. ${ }^{10}$

A multitude of reasons have been reported in the literature that result in the failure of crowns and bridges. ${ }^{5,8,11,14}$ In this study it was found that the most common cause of failure was due to biologic reasons (87.2\%); with endodontic failures accounting for more than half of the failed restorations. Endodontic failures are likely to occur when the primary root canal treatment provided was not up to the standard principles. ${ }^{15,16}$ This can result in pain and swelling which may necessitate the removal of a prosthesis to carry out retreatment or retreatment through the already existing prosthesis; thereby resulting in failure of crowns and bridges. ${ }^{5}$ Such findings are present in the literature, which has shown that pulpal and root canal problems are a common cause of failure of fixed dental prosthesis. ${ }^{10}$

According to this study the second most common cause of failure in fixed restorations was secondary caries. This finding is similar to a study conducted by Cheung GS et al. ${ }^{10}$ Similarly, other studies found secondary caries to be the most common cause of prosthesis failure. ${ }^{13,16-18}$ This high rate of failure due to caries may be explained in part by the less than optimal oral hygiene practices of the participants in this study. This study showed more than half (55.6\%) of the participants brushed their teeth only once daily along 
with no other cleaning aid. To maintain near ideal plaque control, brushing at least twice daily along with flossing is recommended. ${ }^{18}$ It is therefore important that good oral hygiene practices are reinforced in patients when they are provided with any dental prosthesis and they be reiterated at every follow up visit. Mechanical failures accounted for only one-tenth of the failures in porcelain fused to metal restorations, while no case of mechanical failure was reported in the metal crowns. Dislodgement of crowns was the most common mechanical failure reported. This can be partially explained by the fact that most of these restorations were found on posterior teeth which are subjected to higher forces of mastication; thus having a higher chance of dislodgement. ${ }^{19}$

The results of the present study reported more failure of the porcelain fused to metal restorations than the all-metal restorations. Even though other studies have reported a similar trend, the results of this study should be seen with caution as the number of all-metal crowns examined in this study were very few. ${ }^{13,14}$ To correctly compare the failure rate of metal restorations to porcelain fused to metal restoration, a case-control study can be carried out in the future that studies an equal number of restorations in each group. Porcelain fused to metal restorations in this study lasted for 4.9 years, while metal restorations lasted for only around 11 months. Memon and Ghani also

report a similar life span of porcelain fused to metal restorations. ${ }^{20,21}$ Prasad et $\mathrm{al}^{13}$ however found that metal restorations had a much longer life span of 8.5 years as compared to porcelain fused to metal restorations, that were serviceable for 7 years.

Results of this study report an equal number of failed restorations in both the maxilla $(50.3 \%)$ as well as the mandible (49.7\%); with more restorations located in the posterior region. Restorations replacing tooth structure in the posterior region of the arch had a shorter life span of 4.3 years as compared to those present in the anterior region i.e. 6.4 years. Similarly, Saleem et al ${ }^{23}$ also found that $60 \%$ of failed restorations were located in the posterior segment of the arch. These findings were in contrast to a study carried out by Cheung ${ }^{22}$ who found that anterior fixed restorations had a higher failure rate.

In fixed prosthodontics single crowns and fixed partial dentures of up to 3 units are the most commonly used restorations, hence more failures are likely to be reported in such prosthesis. ${ }^{5}$ These observations are reiterated by the results of this study which show that the more than half $(59.5 \%)$ of the failed restorations examined were single-unit crowns, followed by $16 \%$ of 3 unit fixed partial dentures. Similar findings have been published by the General Dental Council of United Kingdom which reported that the majority of the complaints received were about treatment related to crowns (196) and bridges (116). ${ }^{24}$ In general, fixed partial dentures that extend for a span of more than four units present a higher risk of failure. ${ }^{25}$ Randow ${ }^{26}$ reported similar results whereby there were increased failure rates of long span bridges, ranging from $7 \%$ for prostheses of 7 -units to $23 \%$ for prostheses having 10-units. In light of this literature, to reduce the failure rate of a prosthesis and improve prosthesis longevity, long span prosthesis should be avoided. In the present study, however, no relation was found between the span of prosthesis and its life. Single unit crowns and small bridges examined in this study had a life of 4 years approximately, whereas prostheses that were of 5 units or more had a life of more than 7 years. These findings are similar to Walton14 who did not find any relation between prosthesis span and life of prosthesis.

Studies have been conducted in our part of the world to examine the reasons for the failure of fixed prosthesis..$^{20,21,23,27}$ The majority of these studies only focused on the prevalence of failure concerning different variables. This study address the longevity of the fixed prosthesis along with reporting the variables related to failures of fixed prosthesis, such data is present in the western population ${ }^{14}$ but to the best of authors research, no local data was available. Other studies can also be carried out to assess the reasons for failure in fixed prosthesis other than conventional crowns and fixed - fixed partial dentures.

\section{CONCLUSION}

Fixed dental prostheses provide one of the best treatment modalities for replacing teeth. At present the average life of prosthesis at 4 years is less than satisfactory. To improve the longevity of these restorations it is necessary to have proper patient selection, diagnosis, treatment planning, clinical and technical skills. It is also essential to educate the patient about proper oral hygiene and prosthesis maintenance so that the life span of fixed prostheses is increased.

\section{CONFLICT OF INTEREST}

None declared

\section{REFERENCES}

1. Petersen PE, Bourgeois D, Ogawa H, Estupinan-Day S, Ndiaye C. The global burden of oral diseases and risks to oral health. Bull World Health Organ. 2005;83:661-69.

2. Kassebaum NJ, Bernabé E, Dahiya M, Bhandari B, Murray CJ, Marcenes W. Global Burden of Severe Tooth Loss: A Systematic Review and Meta-analysis. J Dent Res. 2014;93:20S-28S. https://doi.org/10.1177/0022034514537828 
Naz A/ Musharraf H/ Jawad A/ Zia K/ Kumar B/ Lone MA

3. Akinboboye B, Akeredolu P, Sofola O, Ogunrinde B, Oremosu O. Utilization of teeth replacement service among the elderly attending teaching hospitals in Lagos, Nigeria. Ann Med Health Sci Res. 2014;4:57-60.

https://doi.org/10.4103/2141-9248.126613

4. The Glossary of Prosthodontic Terms: 9th ed. J Prosthet Dent. 2017;117(5S):e1-e105.

https://doi.org/10.1016/j.prosdent.2016.12.001

5. Briggs P, Ray-Chaudhuri A, Shah K. Avoiding and managing the failure of conventional crowns and bridges. Dent Update. 2012; 39:7884.

https://doi.org/10.12968/denu.2012.39.2.78

6. Chandrakala V, Deepmala S, Srivatsa G. Different classification system for failures in tooth supported fixed partial denture: a systematic review. Int J Prev Clin Dent Res. 2019;6:17-20

https://doi.org/10.4103/INPC.INPC_15_19

7. Patras M, Sykaras N. Esthetic and functional combination of fixed and removable prosthesis. Gen Dent. 2012; 60:e47-54.

8. Manappallil JJ. Classification system for conventional crown and fixed partial denture failures. J Prosthet Dent. 2008; 99:293-98. https://doi.org/10.1016/S0022-3913(08)60064-5

9. Simpson RL. Failures in crown and bridge prosthodontics. J Am Dent Assoc. 1953;47:154-59.

https://doi.org/10.14219/jada.archive.1953.0160

10. Cheung GS. A preliminary investigation into the longevity and causes of failure of single unit extracoronal restorations. J Dent. 1991;19:160-3.

https://doi.org/10.1016/0300-5712(91)90006-K

11. Muddugangadhar BC, Amarnath GS, Sonika R, Chheda PS, Garg A. Meta-analysis of failure and survival rate of implant-supported single crowns, fixed partial denture, and implant tooth-supported prosthesis. J Int Oral Health. 2015;7:11-7.

12. Pjetursson BE, Tan K, Lang NP, Brägger U, Egger M, Zwahlen M. A systematic review of the survival and complication rates of fixed partial dentures (FPDs) after an observation period of at least 5 years. Clin Oral Implants Res. 2004;15:654-66.

https://doi.org/10.1111/j.1600-0501.2004.01119.x

13. Prasad D. K, Hedge C, Desai H. A survey to assess the failures in fixed partial dentures. Int J Recent Sci Res. 2017;8:18770-3.

14. Walton JN, Gardner FM, Agar JR. A survey of crown and fixed partial denture failures: length of service and reasons for replacement. J Prosthet Dent. 1986;56:416-21.

https://doi.org/10.1016/0022-3913(86)90379-3

15. Iqbal A. The factors responsible for endodontic treatment failure in the permanent dentitions of the patients reported to the college of Dentistry, the University of Aljouf, Kingdom of Saudi Arabia. J Clin
Assessment of failure of prostheses in fixed prosthodontics

Diagn Res. 2016;10(5):ZC146-8.

https://doi.org/10.7860/JCDR/2016/14272.7884

16. Schwartz NL, Whitsett LD, Berry TG, Stewart JL. Unserviceable crowns and fixed partial dentures: life-span and causes for loss of serviceability. J Am Dent Assoc. 1970;81:1395-401.

https://doi.org/10.14219/jada.archive.1970.0398

17. Näpänkangas R, Salonen-Kemppi MA, Raustia AM. Longevity of fixed metal ceramic bridge prosthesis: a clinical follow-up study. J Oral Rehabil. 2002;29:140-45.

https://doi.org/10.1046/j.1365-2842.2002.00833.x

18. Schüz B, Sniehotta FF, Wiedemann A, Seemann R. Adherence to a daily flossing regimen in university students: effects of planning when, where, how and what to do in the face of barriers. J Clin Periodontol. 2006; 33:612-19.

https://doi.org/10.1111/j.1600-051X.2006.00967.x

19. Gogna R, Jagadish S, Shashikala K, Keshava Prasad B. Restoration of badly broken, endodontically treated posterior teeth. J Conserv Dent. 2009; 12:123-28.

https://doi.org/10.4103/0972-0707.57637

20. Ghani F, Memon MR. Complications in metal ceramic fixed dental prosthesis among patients reporting to a teaching dental hospital. LUMHS 2010; 09:17-22.

21. Memon MR, Ghani F. Reasons and problems in dislodged metal ceramic fixed partial dentures presented for recementation by patients. J Pak Dent Assoc 2007;16:13-9.

22. Cheung GS, Dimmer A, Mellor R, Gale M. A clinical evaluation of conventional bridgework. J Oral Rehabil. 1990; 17:131-36 https://doi.org/10.1111/j.1365-2842.1990.tb01401.x

23. Saleem T,Amjad F, Bhatti MUD. Complications associated with tooth supported fixed dental prosthesis amongst patients visiting University College of Dentistry Lahore. Pak Oral Dent J 2013;33:20711.

24. Helping you put things right. Dental Complaints Service Annual review - 2009/10

25. Foster LV. The relationship between failure and design in conventional bridgework from general dental practice. J Oral Rehabil 1991;18:491-95.

https://doi.org/10.1111/j.1365-2842.1991.tb00070.x

26. Randow K, Glantz PO, Ziiger B: Technical failures and some related clinical complications in extensive fixed prosthodontics. Acta Odontol Scand 1986;44:241-255

https://doi.org/10.3109/00016358608997726

27. Zafar N, Ghani F. Common Post-fitting Complications in Toothsupported Fixed-Fixed Design Metal-Ceramic Fixed Dental Prosthesis. Pak J Med Sci. 2014;30:619-25

https://doi.org/10.12669/pjms.303.5599 